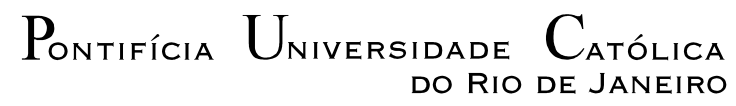

Marco Antônio da Costa Camelo

\title{
CURRÍCULO, PRÁTICA DOCENTE E LITERATURA DE EXPRESSÃO AMAZÔNICA
}

Tese de Doutorado

Tese apresentada ao Programa de Pós-Graduação em Educação Brasileira da PUC-Rio como parte dos requisitos para a obtenção do título de Doutor em Educação Brasileira.

Orientador: Marcelo Gustavo Andrade de Souza

Rio de Janeiro

Setembro de 2010 


\title{
CURRÍCULO, PRÁTICA DOCENTE E LITERATURA DE EXPRESSÃO AMAZÔNICA
}

\begin{abstract}
Tese apresentada como requisito parcial para obtenção do grau de Doutor pelo Programa de Pósgraduação em Educação do Departamento de Educação do Centro de Teologia e Ciências Humanas da PUC-Rio. Aprovada pela Comissão Examinadora abaixo assinada.
\end{abstract}

Prof. Marcelo Gustavo Andrade de Souza

Orientador

Departamento de Educação daPUC-Rio

Prof. a Sônia Kramer

Presidente

Departamento de Educação da PUC-Rio

Prof. ${ }^{\mathrm{a}}$ Tânia Dauster Magalhães e Silva

Departamento de Educação da PUC-Rio

Prof. Augusto César Gonçalves e Lima

UFF

Prof. a Cláudia Miranda

UFF

Profa. Denise Berruezo Portinari

Coordenadora Setorial do Centro de Teologia e Ciências Humanas

PUC-Rio

Rio de Janeiro, 29 de Setembro de 2010. 
Todos os direitos reservados. É proibida a reprodução total ou parcial do trabalho sem a autorização da universidade, do autor e do orientador.

Marco Antônio da Costa Camelo

Marco Antônio Camelo é Licenciado Pleno em Letras (Português-Francês), Mestre em Educação Docência Universitária pelo Instituto Pedagógico Latino Americano e Caribenho (IPLAC - República de Cuba -Havana). Foi bolsista do CNPq nas modalidades de Aperfeiçoamento em Pesquisa e Mestrado. Foi bolsista estadual (Governo do Estado do Pará / Universidade do Estado do Pará) durante o doutorado. Integra o Grupo de Pesquisa CUMA (Culturas e Memórias da Amazônia), coordenado pela Profa. Dra. Josebel Akel Fares da UEPA e durante a permanência no Rio de Janeiro fez parte do GRUPEM (Grupo de Pesquisa Educação e Mídia) coordenado pela Profa. Dra. Rosália Duarte. Professor Assistente IV do Departamento de Língua e Literatura do Centro de Ciências Sociais e Educação da Universidade do Estado do Pará e Professor do Quadro I do Curso de Licenciatura em Letras e Bacharelado em Tradutor/Intérprete da Faculdade Integrada Brasil Amazônia. Tem trabalhado como professor de ensino superior desde o ano de 1987, tecendo e mantendo relações entre os movimentos sociais, a escola e o mundo acadêmico.

Ficha Catalográfica

Camelo, Marco Antonio da Costa

Currículo, prática pedagógica e literatura de expressão amazônica / Marco Antonio da Costa Camelo ; Orientador: Marcelo Gustavo Andrade de Souza ; Co-orientadora: Josebel Akel Fares. 2010.

191 f. : il. (color.) ; $30 \mathrm{~cm}$

Tese (Doutorado em Educação) - Pontifícia Universidade Católica do Rio de Janeiro, Rio de Janeiro, 2010.

Inclui bibliografia

1. Educação - Teses. 2. Currículo. 3. Cultura escolar. 4. Diversidade cultural. 5. Literatura amazônica. 6. Cotidiano escolar. I. Souza, Marcelo Gustavo Andrade de. II. Fares, Josebel Akel. III. Pontifícia Universidade Católica do Rio de Janeiro. Departamento de Educação. IV. Título. 


\section{À memória de meu pai}

Obrigado, meu pai, por tudo o que me ensinaste na vida. Acompanhaste-me até aonde pudeste. $\mathrm{O}$ ciclo da vida interceptou alguns sonhos. Chego ao fim de mais uma caminhada, com a certeza de que sempre estiveste ao meu lado. Perdão se não disse tudo o que sentia por você. Sei que algum dia terei esta oportunidade.

Este trabalho é seu. Muito obrigado por tudo. A sua bênção! 


\section{AGRADECIMENTOS}

Agradeço sobremaneira a Deus pela força espiritual e acompanhamento nesta empreitada de minha vida. Obrigado por tudo, Senhor!

Agradeço a minha família, em especial ao Miguel, meu irmão, por toda a ajuda recebida durante a minha permanência na cidade do Rio de Janeiro. Você sabe do que eu estou falando. Obrigado por tudo, mano!

Agradeço a Universidade do Estado do Pará - UEPA e a Pontifícia Universidade Católica do Rio de Janeiro pela oportunidade que me proporcionaram de realizar meu curso de doutorado.

Agradeço muito especialmente aos professores do Departamento de Educação da PUC pelo carinho e respeito que a mim dedicaram nesses quase cinco anos de estudo.

O meu muito obrigado as Profas. Dras. Sônia Kramer, Aparecida Mamede, Tânia Dauster e Rosália Duarte pela dedicação e orientação nos primeiros passos de minha tese. Suas sugestões e orientações foram fundamentais para que eu chegasse aonde cheguei.

Um agradecimento especial ao meu orientador, Prof. Dr. Marcelo Andrade, pela cuidado que teve comigo e com a minha tese me ajudando de forma meticulosa e paciente a construir passo a passo meu conhecimento e, sobretudo a compreender o que é fazer uma tese de doutorado. Obrigado pelas primeiras revisões e por estas últimas também. Obrigado pelas sugestões de leituras e pelos livros gentilmente presenteados. Eles foram de uma utilidade singular em minha percepção da pesquisa.

Obrigado a minha co-orientadora, Profa. Dra. Josebel Akel Fares, pelas preciosas informações sobre cultura e literatura de expressão amazônica. Obrigado também pelas sugestões de leitura e pelas "dicas" de como proceder em minha pesquisa de campo. Você não tem idéia do quanto me ajudou naquela primeira orientação no momento em que me mostrou aqueles seus arquivos com uma grande parte da história da SEMEC a qual você ajudou escrever. 
Obrigado a todos os meus amigos de turma do DINTER: Elisa, Lurdinha, Eunápio, Paraense, Sinaida, Renato, Waldir, Eli, Irene, Kelly, Roberto, Sued e Natanael.

Obrigado a minha professora particular de inglês, Ana Lilia Carvalho Rocha.

Agradeço ainda o apoio financeiro da Universidade do Estado do Pará por meio da Bolsa Estadual que, efetivamente, possibilitou a minha dedicação a esta pesquisa.

Aos técnicos da Secretaria Municipal de Educação e Cultura (SEMEC-PMB).

Aos professores e técnicos da Escola Alfredo Chaves por tudo o que me ensinaram nesses cinco anos de convivência. 


\section{RESUMO}

Camelo, Marco Antônio da Costa. Souza, Marcelo Gustavo Andrade de. Currículo, Prática pedagógica e Literatura de Expressão Amazônica. Rio de Janeiro, 2010. 191p. Tese de Doutorado - Departamento de Educação, Pontifícia Universidade Católica do Rio de Janeiro.

A tese visa analisar e compreender, a partir da perspectiva dos estudos curriculares e dos estudos sobre a prática pedagógica, os saberes e as práticas de professores do ensino fundamental e as matrizes curriculares de ensino propostas pela Secretaria Municipal de Educação e Cultura de Belém-Pará, na perspectiva da literatura de expressão amazônica. O trabalho parte de duas questões orientadoras: (1) Como a prática pedagógica de professores que atuam no ensino fundamental leva em consideração o ensino de literatura de expressão amazônica? (2) As matrizes curriculares do ensino fundamental no município de Belém contemplam o ensino de literatura de expressão amazônica? Neste sentido, foi observada a prática pedagógica de professores do ensino fundamental de uma escola municipal de ciclos localizada no distrito de Icoaraci (Belém-Pará), bem como foi analisado as matrizes curriculares da SMEC, com especial ênfase à literatura de expressão amazônica. As questões mais específicas da pesquisa foram: (1) As matrizes curriculares, utilizadas no ensino fundamental do município de Belém, podem ser consideradas como o resultado de um modelo pedagógico que identifica os aspectos da literatura de expressão amazônica? (2) Os elementos sócio-culturais diretamente relacionados ao universo literário amazônico no ensino fundamental são valorizados pelo professor? Se sim, como? Se não, por quê? A metodologia consistiu, principalmente, de análise das matrizes curriculares e de observação do universo escolar. Os sujeitos da investigação foram os professores que atuam na escola de ensino fundamental selecionada.

\section{Palavras-chave}

Currículo; diversidade cultural; literatura amazônida; cotidiano escolar. 


\section{ABSTRACT}

Camelo, Marco Antônio da Costa. Souza, Marcelo Gustavo Andrade de (Advisor). Curriculum, Pedagogical Practice and Amazonic Literature. Rio de Janeiro, 2010. 191p. PhD thesis - Departmento de Educação, Pontifícia Universidade Católica do Rio de Janeiro.

The thesis 'Curriculum, Pedagogical Practice and Amazonic Literature' aims to analise and comprehend, from the perspective of curriculum studies and from the studies about pedagogical practice, the knowledge and practices of teachers from regular school in Amazonic Literature and the curriculum matrix of learning proposed by the Municipal Secretary of Education and Culture from Belém,- Pará. Two scientific questions were determinant to the accomplishment of this research: (1) How the pedagogical practice of teachers that work in primary school take into consideration the Amazonic literature teaching? (2) Do the curriculum matrix of primary school in the city of Belem have within them the teaching of Amazonic Literature? I studied the pedagogical practice of primary teachers in a municipal schools of cycles located in the district of Icoaraci (BelémPará), analyzing the curriculum matrix, with special emphasis to Amazonic Literature. The main questions were: (1) The insertion of elements in the amazonic literary universe, in primary school, reveals itself, in the teachers practice, as a form of valuing the cultural and conceptual universe ? (2) The curriculum matrix used in the primaryu school in the city of Belem could be considered as a resulto $\mathrm{f}$ a pedagogical model that idientifies the aspects of amazonic Literature? How does the primary teacheruses the curriculum matrix established by SEMEC in the aspects related to the Amazonic Literature Teaching? Are the socio cultural elements direclty related to the amazonic literary universe in the primary education valued by by the teacher? If so, how? If not, why? The methodology was disposed like that: Curriculum matrix analysis and observation of the school universe. The teachers that work in the primary school selected were the subjects of investigation.

\section{Keywords}

Curriculum; Amazonic Literature; cultural diversity; school routine. 


\section{SUMÁRIO}

$\begin{array}{ll}\text { 1. Introdução } & 11\end{array}$

2. Currículo, cultura e literatura 21

2.1. Escola, currículo e cultura 21

2.2. Currículo, multiculturalismo e interculturalidade 28

2.3. Escola e ensino de literatura 41

2.4. Universo literário amazônida 51

2.5. Literatura de expressão amazônica e Escola Cabana 62

3. O que dizem os documentos? 76

3.1. Primeira aproximação aos documentos 77

3.2. Os documentos contam e ocultam a história 80

3.3. Os documentos e a identidade no plural 89

3.3.1. Identidade amazônica 91

3.3.2. Práticas pedagógicas em literatura de expressão amazônica 97

3.3.3. Poéticas das narrativas orais e literatura

de expressão amazônica 102

3.3.4. Texto literário, pluralidade cultural e currículo 110

4. O que revela a observação? 117

4.1. Os caminhos de entrada no campo 118

4.2. A Escola Alfredo Chaves, o campo de pesquisa 123

4.3. A observação: por dentro da escola 126

4.3.1. Como a gestão escolar influencia na cultura da escola? 128

4.3.2. O clima escolar e o clima em sala de aula 137

4.3.3. Os professores e suas práticas 141

4.3.3.1. Os professores 143

4.3.3.2. A rotina das aulas 146

4.3.3.3. Estilos pedagógicos e ensino de literatura regional 148

4.3.3.4. Tarefas escolares e deveres de casa 157

4.3.3.5. O uso do livro didático 161 
4.3.3.6. E as crianças, como participam?

162

5. Conclusão

169

6. Referências Bibliográficas

175

Anexos

183 